\title{
Discussion on strengthening construction technology of sluice in water conservancy project
}

\author{
Sannan $\mathrm{Wu}^{1, \mathrm{a}}$, Yingchun Wang ${ }^{2, \mathrm{~b}}$ \\ ${ }^{1}$ School of management, Tianjin University of Technology, Tianjin 300384, China \\ ${ }^{2}$ School of management, Tianjin University of Technology, Tianjin 300384, China
}

\begin{abstract}
With the development of China's social economy and science and technology, all aspects of the construction are also growing rapidly, water conservancy project is one of the very important infrastructures in China, for promoting the development of China's economy and science and technology has a positive significance. With the promotion of social economy and science and technology, the number of water conservancy projects has been greatly improved. At present, water conservancy projects of different sizes, large and small, are being carried on continuously. With the vigorous development of water conservancy project, higher requirements are put forward for water conservancy project construction. Sluices plays an extremely important role in water conservancy project, sluice is built on the river to control the flow of important facilities, water conservancy construction of downstream river drainage, water supply, flood control has an important role in flood season, therefore, guaranteeing the quality of lock of water conservancy project on the surrounding residents' life safety and property safety is of great significance. This paper expounds the significance of sluice reinforcement in water conservancy projects, analyzes on the technical points of sluice reinforcement, and further discusses them with practical examples for reference.
\end{abstract}

\section{Introduction}

Lock as an important part of water conservancy project, its construction quality relates the security and reliability of the whole project, but in a variety of factors, under the joint action of locks easily because of aging, corrosion and damage problem can meet the operation requirements at this stage, Therefore, it is necessary to use effective reinforcement technology to eliminate hidden dangers and better serve the development of water conservancy undertakings.

\section{The significance of floodgate reinforcement}

Gate in hydraulic engineering in general is located in a river or channel, it is mainly used for control and regulation of river flow, water level, if closed can raise the upstream water level play a role of detention, if open can be carried out on the river downstream water supply, so the rational use of sluice has remarkable economic benefits not only, still conduce to the healthy development of water conservancy projects. Lock of water conservancy projects, however, may arise during the use of different types, different levels of quality problems, such as the lock chamber structure, displacement exceeds bid, concrete cracks in concrete structure and so on, the bearing capacity decreases: energy dissipation impingement facility with undermine longer duration of use, the energy dissipation loss of impingement, buried under the security hidden danger; The deformation of the gate girder, the failure of the face plate, the defects of the concrete surface and the failure of the foundation pose a threat to the safety and stability of the water conservancy project. And this and early technology is limited, disrepair, flood, silt, earthquake and other external forces, as well as the human operation is not standard, management is not in place and so on have a great relationship. If we want to ensure the safe and reliable operation of water conservancy project, we must do a good job in the reinforcement work of sluice, which requires us to base on the reality, optimize the reinforcement plan, grasp the key points of technology, strengthen the construction management, strive to improve the quality of sluice reinforcement and extend the service life.

\section{Discussion on the construction example of sluice reinforcement}

\subsection{General situation of sluice}

Known to the water conservancy project as flood control, drainage, irrigation, washout pollution, shipping, such as a variety of functions, including locks for two-way water retaining, main effect for the tidal flood control, water diversion for irrigation, etc., the hole number and width of the 10 hole and $150 \mathrm{~m}$ respectively, and the flow design value is $1020 \mathrm{~m}$ after passing $/ \mathrm{m}$, don't use is flat steel gate

a1277233660@qq.com, bycwang@sina.com 
and bottom points and $1.2 \mathrm{~m}$ thick reinforced concrete, sluice based and gate pier foundation is respectively 800 and $1200 \Phi \Phi$ drilling pouring piles. The monitoring data shows that the seepage anomaly on the river side of the sluice often occurs, which is proved to be caused by the failure of impermeable steel plate. Meanwhile, the foundation of the sluice in the soft soil layer has some uneven subsidence, which has a serious impact on the normal performance of energy dissipation and antiscouring function. Therefore, effective reinforcement measures are urgently needed.

\subsection{Design and optimize reinforcement scheme}

In order to ensure the reasonable and effective reinforcement technology, should be to review of relevant parameters, the review found that the existing tidal and gate spillway contour length meet the design specification, but the seepage slope abnormal level of floor in the period of five parameters, show the original steel sheet pile seepage prevention in failure state are in urgent need of sluice foundation, so combined with similar engineering experience, the design of high pressure jet grouting pile and steel sheet pile cut-off two technical scheme comparison. The high spray cutoff wall is generally set around the sluice, and its horizontal and longitudinal axes are parallel to the horizontal and longitudinal axes of the sluice respectively. Firstly, flexible materials are used to seal the joint positions of bottom plates on both the inside and outside of the sluice gate, and then the high spray cutoff wall is enclosed, which needs to be realized with the help of air pipe, slurry pipe and cement clay slurry of 42.5 strength. Grouting holes with a spacing of $1.70 \mathrm{~m}$ are divided into I sequence rotary jet grouting pile and II sequence pendulum jet grouting pile. The bottom of the cutoff wall deep into the bottom of the silt layer should be greater than $1.0 \mathrm{~m}$, the depth can be controlled within 20.6 28.6m, and the transverse and longitudinal lengths are set at $366.6 \mathrm{~m}$ and $32.8 \mathrm{~m}$ respectively. The steel sheet pile impervious wall is a re-construction project, that is, it is set on the river side inside and outside the sluice bottom, and the height of the impervious wall and the steel sheet pile top are respectively $-5.20 \mathrm{~m}$ and $-5.50 \mathrm{~m}$. Larsen III steel sheet pile of PU $400 \times 125 \times 13$ is adopted. Meanwhile, the concrete cover beam is designed and the flexible waterproof is used to connect the sluice bottom and the impervious wall. After comparison, it is found that although the scheme of high-shotcrete impermeable wall has simple technology, high efficiency, less pollution and good effect, it can strengthen the impermeable ability through the formation of consolidation body, and can be closely combined with the formation, which is beneficial to the improvement of composite impermeable effect, but it is not easy to ensure the continuity of the wall if the formation is viscous or the groundwater flow rate is too large. Although the application of steel sheet pile impermeable wall is fast and convenient, the technology is mature, and the requirements for soil layer are not too high, which makes the seepage diameter of sluice increase significantly, greatly reduces the seepage slope, and can meet the design requirements, but the disadvantage lies in the high cost. Therefore, considering that there is a certain suspension under the sluice foundation at present, and it is difficult to form a continuous cutoff wall, the steel sheet pile cutoff wall is finally selected as the reinforcement scheme.

\subsection{Key points of steel plate cutoff wall construction}

The length of the seepage control wall of the newly built steel sheet pile is designed to be $172 \mathrm{~m}$, which is located in the inner and outer river sides of the bottom plate of the sluice chamber respectively. The seepage control and reinforcement effect can be guaranteed by forming the sealing gate foundation step by step. Specifically, under the condition that there is $9 \mathrm{~m}$ steel sheet pile impervious wall on the river outside no. 1 and No. 2 sluice hole, new steel sheet pile is built according to the interval control of $0.5 \mathrm{~m}$. Meanwhile, the width of other parts of the groove is set as $0.5 \mathrm{~m}$ and is arranged next to the sluice bottom plate. The top of the steel sheet pile should be embedded into the C30 concrete cover beam, but the film bag concrete with the thickness of $0.3 \mathrm{~m}$ should be covered first. In order to ensure that the elevation of various parameters meets the design requirements, the original steel sheet pile outside the no.1 and No.2 gate hole should be cut underwater to make its top elevation lower than $5.50 \mathrm{~m}$. When reviewing the bearing capacity of steel sheet pile, it can be calculated based on the empirical parameter method and appropriately transformed to ensure the reliability of the reinforcement scheme. Finally, the data in Table 1 is obtained, which shows that the strong bearing capacity of steel sheet pile over meets the design requirements, indicating that the reinforcement scheme is reasonable and effective.

Table 1. Reinforcement scheme

\begin{tabular}{|c|c|c|c|c|}
\hline The serial number & project & unit & outside & inside \\
\hline Z & $\begin{array}{c}\text { Calculation of vertical bearing } \\
\text { capacity of pile foundation }\end{array}$ & $\mathrm{m}$ & 18 & 18 \\
\hline $\mathbf{1}$ & Design pile length & $\mathrm{m}$ & 0.80 & 0.80 \\
\hline $\mathbf{2}$ & Pile body circumference & & & \\
\hline
\end{tabular}




\begin{tabular}{|c|c|c|c|c|}
\hline 3 & Pile tip area & $\mathbf{M}^{2}$ & 0.01 & 0.01 \\
\hline 4 & $\begin{array}{l}\text { Penetration depth of pile } \\
\text { foundation }\end{array}$ & $\mathrm{m}$ & 18 & 18 \\
\hline 5 & Pile foundation depth in silt layer & $\mathrm{m}$ & 18 & 18 \\
\hline 6 & $\begin{array}{l}\text { Standard value of ultimate lateral } \\
\text { resistance of silt layer }\end{array}$ & $\mathrm{kP}_{\mathrm{a}}$ & 20 & 20 \\
\hline 7 & $\begin{array}{l}\text { Standard value of total ultimate } \\
\text { lateral resistance of single pile }\end{array}$ & $\mathrm{kN}$ & 144 & 144 \\
\hline 8 & safety factor & $\mathrm{kN}$ & 2 & 2 \\
\hline 9 & $\begin{array}{l}\text { Characteristic value of vertical } \\
\text { bearing capacity of single pile }\end{array}$ & $\mathrm{kN}$ & 72 & 72 \\
\hline 10 & $\begin{array}{l}\text { Standard value of vertical ultimate } \\
\text { bearing capacity of single pile }\end{array}$ & $\mathrm{kN}$ & 144 & 144 \\
\hline 11 & $\begin{array}{l}\text { Average vertical force of } \\
\text { foundation pile }\end{array}$ & $\mathrm{kN}$ & 36.04 & 36.04 \\
\hline 12 & $\begin{array}{l}\text { Characteristic value of vertical } \\
\text { bearing capacity of foundation pile }\end{array}$ & $\mathrm{kN}$ & 72 & 72 \\
\hline 13 & $\mathrm{~N}_{\mathrm{k} \leq} \leq \mathrm{R}$ & & meet & meet \\
\hline
\end{tabular}

\section{Quality control measures for water conservancy projects}

\subsection{Improve the supervision level of water conservancy projects}

In the construction stage of the project, it is necessary to do a good job in the supervision work. The supervision personnel should supervise the water conservancy project in strict accordance with the relevant provisions, have a good understanding of the construction organization's construction plan, construction equipment and funds, and supervise and inspect the construction activities of the contractor in the authorized project and part of the project. Keep watch record and write construction log. Improve the professional level and quality of supervisors of water conservancy projects.

\subsection{Regular maintenance}

For water conservancy projects, regular maintenance work is very important, professional staff should be organized to regularly check the situation and stability of the sluicles, pay attention to some small problems, to avoid potential safety hazards.

\section{Conclusion}

Water conservancy project belongs to the current social necessary for the convenience of construction, to meet the water application, farmland irrigation and flood control and disaster mitigation, and other requirements, and lock instability resulting in a decline in the overall usability of the whole water conservancy project, the place on put together is narrated, in water conservancy engineering, application of sluice reinforcement construction technology, to ensure the application effect of technology, to be executed in strict accordance with construction technical scheme, key points of the application of control technology. In addition, it is also necessary to control common problems in reinforcement construction, including deformation problems and foundation seepage problems, so as to control the quality of engineering construction operations to the greatest extent, so as to ensure the good operation of water conservancy system.

\section{References}

1. Gao Yang. Reinforcement design analysis of Pine Mouth Inlet sluicer in Qingyuan County, Fushun city [J]. Shaanxi Water Conservancy,2019(9):183-185.

2. Huang Pingdan. Application analysis of sluice reinforcement construction technology in water conservancy projects $[\mathrm{J}]$. Low carbon world,2019,9(8):84-85.

3. Deng Qi-yue. Discussion on construction Technology of sluice Reinforcement in water conservancy projects $[\mathrm{J}]$. Building Materials and Decoration, 2019(22):315-316. 
4. Hu Lei. Application analysis and Discussion of Sluice Reinforcement Construction Technology in Water Conservancy Projects [J]. Urban Construction Theory Research (electronic Version), 2019(6):170.

5. Li Huijing. Research on construction Technology of Sluice Reinforcement in Water Conservancy Projects [J]. Ju She, 2018(9):54.

6. Lin Chun. Application analysis of sluice reinforcement construction technology in water Conservancy Projects [J]. Building Materials and Decoration, 2016(33):244-245. 